\title{
Manfred Brauneck, Die Deutschen und ihr Theater
}

\section{Aline Le Berre}

\section{OpenEdition \\ Journals}

Édition électronique

URL : http://journals.openedition.org/ifha/9356

DOI : $10.4000 /$ ifha.9356

ISSN : 2198-8943

Éditeur

IFRA - Institut franco-allemand (sciences historiques et sociales)

\section{Référence électronique}

Aline Le Berre, " Manfred Brauneck, Die Deutschen und ihr Theater », Revue de I'IFHA [En ligne], Date de recension, mis en ligne le 30 juillet 2018, consulté le 24 septembre 2020. URL : http:// journals.openedition.org/ifha/9356 ; DOI : https://doi.org/10.4000/ifha.9356

Ce document a été généré automatiquement le 24 septembre 2020.

(CIFHA 


\title{
Manfred Brauneck, Die Deutschen und ihr Theater
}

\author{
Aline Le Berre
}

\section{RÉFÉRENCE}

Manfred Brauneck, Die Deutschen und ihr Theater. Kleine Geschichte der "moralischen Anstalt « - oder: Ist das Theater überfordert?, Bielefeld: Transcript Verlag, 2018, 179 p., $24,99 €$ 
Manfred Brauneck dresse un panorama fourni du théâtre allemand depuis le XVIII ${ }^{\mathrm{e}}$ siècle. Constatant que les Allemands attendent autre chose qu'un simple divertissement, il met en lumière le rôle du théâtre dans la société. Son ouvrage ambitionne d'évoquer le contexte historique et philosophique qui a présidé à l'élaboration des diverses œuvres emblématiques. C'est pourquoi il mentionne les événements et les conceptions qui ont marqué une époque donnée au niveau européen avant de s'intéresser aux pièces allemandes. Cela lui permet une mise en perspective tout à fait originale.

Ainsi, il explique par le développement de l'empirisme au XVIII ${ }^{\mathrm{e}}$ siècle en Angleterre le fait que le théâtre ne s'adresse plus à

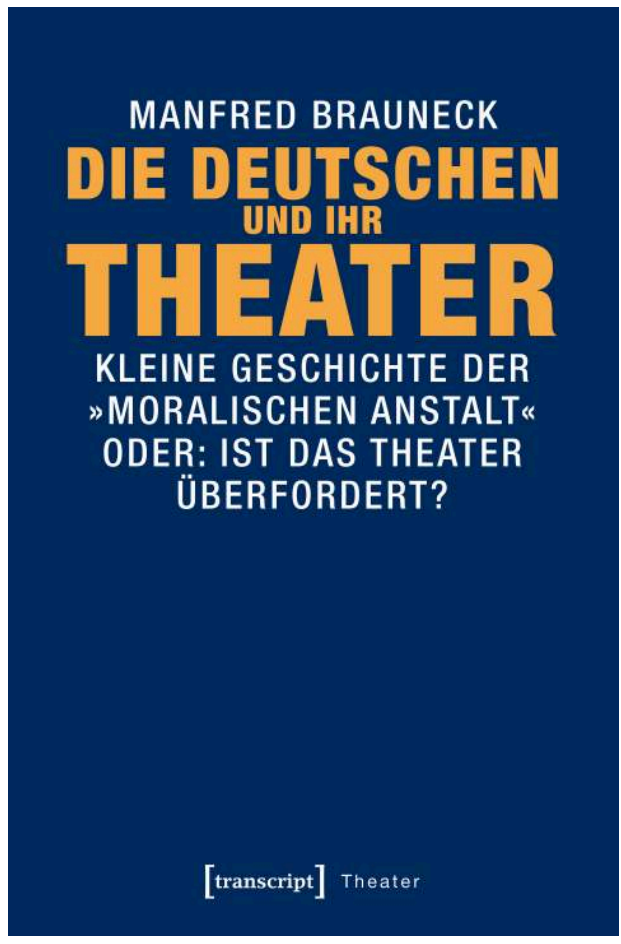
l'aristocratie mais aux bourgeois, et part de la création de Georges Lillos, The London Merchant or The History of George Barnwell, mise en scène en 1731 et présentée en Allemagne à Leipzig en 1752, avant de passer en revue les pièces allemandes typiques $\mathrm{du}$ drame bourgeois, comme Miß Sara Sampson, Emilia Galotti de Lessing et Kabale und Liebe de Schiller. Il souligne leur côté novateur puisqu'elles mettent l'accent sur les sentiments des personnages dans des situations de la vie courante : rivalité, jalousie, conflits familiaux, etc. Cette forte composante affective tranche par rapport à la retenue et à la domination de soi préconisées par l'aristocratie et caractérisant le théâtre classique du XVII ${ }^{\mathrm{e}}$ siècle.

De même, il constate que le XIX ${ }^{\mathrm{e}}$ siècle a dû s'adapter à un public de masse, ce qui a engendré l'avènement du réalisme, puis du naturalisme. Il souligne l'influence de Zola, d'Ibsen, de Tolstoï et de Strindberg sur le naturalisme allemand dont l'un des principaux représentants, Gerhard Hauptmann, met « la question sociale » au centre de ses préoccupations.

En revanche le début $d u X X^{\mathrm{e}}$ siècle se détourne du réalisme et du naturalisme pour privilégier le rêve et l'oubli du quotidien. On a abandonné les objectifs éducatifs d'un Lessing et d'un Schiller en faveur d'un vécu individuel subjectif, position qu'illustre le symboliste belge Maurice Maeterlinck. La psychanalyse de Freud s'inscrit également dans cette perspective qui se retrouve dans les productions de l'Autrichien Max Reinhardt, « médiateur entre le rêve et la réalité » selon Thomas Mann.

La période nazie, évoquée brièvement dans l'ouvrage, constitue une coupure tragique, même si Gustaf Gründgens, qui dirigeait le théâtre de Berlin, s'est efforcé de maintenir la bonne renommée de l'institution, en écartant « les pièces de propagande par trop plates ", tout en donnant des gages au régime. Finalement, le volume se tourne vers la période contemporaine, marquée au départ par un besoin considérable de rattraper le temps perdu après le nazisme et un grand enthousiasme pour le théâtre, considéré comme un moyen de défendre la culture. 
Sur ce point également, $M$. Brauneck se montre très éclectique et pédagogue, évoquant le pré-expressionisme de Borchert dans sa célèbre pièce Draußen vor der Tür, interdite dans la zone d'occupation soviétique car considérée comme défaitiste et larmoyante, mais aussi Des Teufels General de Karl Zuckmayer, et les pièces de Jean Anouilh en vogue alors à l'ouest mais refusées à l'est. Puis il passe en revue l'existentialisme de Sartre et le théâtre de l'absurde avec Ionesco et Beckett, surtout appréciés sur les scènes de la RDA.

Il a en outre le mérite de réserver une place importante au théâtre de la seconde moitié $\mathrm{du} \mathrm{XX}^{\mathrm{e}}$ siècle, qui cherche à régler des comptes avec le nazisme, comme Rolf Hochhuth avec Der Vertreter (1963) ou Peter Weiss dans Die Ermittlung s'inspirant des documents du procès d'Auschwitz à Francfort. Il mentionne également des metteurs en scène marquants comme Fritz Kortner qui, revenu d'émigration des États-Unis, révolutionne la représentation des drames schillériens dans la perspective de l'expérience du nazisme. Ainsi, dans Don Carlos, F. Kortner campe des héros accablés et non pas triomphants, une Église catholique représentée comme l'incarnation d'un régime totalitaire sous les traits d'un Grand Inquisiteur contrefait à la manière d'un gnome. M. Brauneck consacre aussi à la situation en RDA des analyses détaillées, concernant en particulier le théâtre brechtien, puis celui de Heiner Müller, créateur d'un théâtre postdramatique dans lequel le spectateur ne doit plus s'identifier aux personnages, comme dans Quartett inspiré de Laclos.

Pour finir, son volume débouche sur le $\mathrm{XXI}^{\mathrm{e}}$ siècle. M. Brauneck constate que la réunification n'a pas été un thème pour le théâtre d'aujourd'hui. Ce dernier n'est plus considéré comme une institution morale selon la vision schillérienne, mais comme un lieu d'introspection, ou un atelier du futur, permettant d'interroger le sens de la vie.

Il s'agit d'un ouvrage clair, bien construit, facile à aborder, et en même temps riche et passionnant, qui pose des questions, suscite des réflexions, s'interroge sur la finalité des créations dramatiques, les ancre dans le courant des idées et des événements, ressuscite un monde fourmillant et cerne les divers acteurs de cette évolution (auteurs, théoriciens, politiques et metteurs en scène). C'est donc une rétrospective sans tabou, non dénuée d'humour et très bien documentée, qui permet de mieux comprendre le théâtre allemand contemporain et de lui rendre justice.

INDEX

Thèmes : Histoire de la culture, Histoire des mentalités

Index chronologique : Période moderne, Époque contemporaine 